\title{
Seed Producer Organization of Farmer: An Experience of Western Terai, Nepal
}

S Dhakal

\begin{abstract}
Use of improved seeds has a vital role in enhancing agricultural production. Agriculture extension has implemented farmers' managed seed multiplication program at the community level to ensure efficient supply of improved seeds. Several success and failure cases of seed multiplication through farmers' organizations were experienced. Therefore, a case study was conducted in the western terai region of Nepal to explore the factors responsible for success/failure of farmers' organizations involved in seed production. The results of the study found that internal factors of group, nature of extension support, quality control mechanism, and seed marketing approaches are the key elements, which affect the performance of farmers' organizations- seed groups and cooperatives. It was also observed that organizations developed in farmers' own initiatives performed better than those formed in external influence. The results of this research suggest that the autonomy of group actions has long term impact on ownership development. Business skills, technical skills and organizational management skills were equally important for the viability of farmers' organizations so far as seed business is concerned.
\end{abstract}

Regional Agriculture Training Centre, Nepalganj

Key words : extension service, farmers' organization, seed production, seed business

\section{Introduction}

Adequate supply of improved quality seeds is a prerequisite for enhancing agriculture production. However, state support is reduced to supply the seeds of field crops in liberalised world (Amstel, et al., 1995) and the private companies moved towards cross pollinated crops, less interested in food crops for subsistence growers (Bengtsson, 2007). As a result, the supply of improved seed from formal sector is only $10 \%$ of total seed used for staple crops in developing countries (Almekinders, et al.1994); rest is supplied through informal sources, for instances farmer's own source or exchange. The quality of such farm saved seeds is questionable, and could be a limiting factor for production increment if the quality is substandard. Smallholder seed enterprise in the absence of large companies, provide a valid alternatives for production and distribution of food crops (Guei, 2010).

Despite various efforts since long in Nepal, the supply of improved seeds from formal sector is about $8 \%$ of total seed requirement (Pokhrel, 2012) for major field crops (cereals, pulses and oilseeds). The formal sources include public, private and community led seed supply in Nepal (Pokhrel, 2012). National Seed Company, Limited (NSCL) and District Agriculture Development Offices (DADOs) are the public sector agencies involved in certified/improved seed production and distribution. DADOs are supporting seed multiplication at the community level through farmers' organization (FOs), such as farmers' groups (FGs) and cooperatives. The endeavours of DADOs comprise the regular programmes and project supported programmes. District Seed Self Sufficiency Programme (DISSPRO), initiated in 1996, is now extended in all 75 districts (CDD, 2011) 
implemented through DADOs. In addition, Commercial Seed Production Programme (CSPP) is being implemented in 16 districts including at the community level since 2007 (CDD, 2011).

Banke and Bardiya districts are 'food bowl' of mid western region, and are getting priority in seed production of major field crops. These districts fall among the 16 districts where CSPP is being implemented in addition to DISSPRO. In Banke, 12 cooperatives and 4 FGs, (DADO, 2011a) and in Bardiya, 4 cooperatives and 6 FGs are actively involved in seed multiplication under the DISSPRO and CSPP (DADO, 2011a; DADO, 2011b). Tracking the past endeavours, Agriculture Resource Centres (ARCs) were promoted by DADOs with the help of Secondary Crop Development Project (SCDP) implemented in 6 districts including Banke and Bardiya from 19891997 to enhance the production and distribution of secondary crops (Lentil, Chickpea, Rajma and rapeseeds) seeds at the local level (ADB, 1999). ARCs had seed processing units, storage structures, and management body selected from members. There were 2 ARCs in each of Banke and Bardiya districts, altogether 4 ARCs, performing well during project period. However, 3 of them could not continue the seed business after the project termination. Only one ARC at Betahani (Banke) remained active, but it was merged with Krishak Upkar Multipurpose Cooperative (KUMC) in 2006 with the aim of achieving synergy in seed multiplication activities.

Several success and failure cases of seed multiplication through farmers' organizations were experienced in Nepal. DISSPRO is widely adopted and cheapest seed producing program with annual production of $40.4 \%$ of the total certified/improved seeds in the country, the volume of seed production under DISSPRO is increasing (Pokhrel, 2012), and thus it can be understood as a successful programme. Unlike DISSPRO, Special Programme in Nepal (SPIN) was not able to develop sustainable mechanism of seed multiplication at community level; the FGs do not became able to continue the seeds production activities after the termination of SPIN (Poudel et al. 2003). Similarly, ARCs developed by SCDP in Banke and Bardiya districts are examples of failure case. Amidst the examples of failed and successful FOs in seed business, it is extremely important to carefully examine the way to establish the FOs viable in seed business. Strengthening such FOs can help meet local demands, as well as supply quality seed to fulfil the national demand (Poudel et al, 2003).

The internal factors of group, service agency support and community factors have significant impact in performance of farmers' organisations (Chamala, 1995). Similarly, the economic benefit for seed producers is one of the important elements for the sustainability of formal seed systems (Louwaars, 1995). Quality of seed is always a key issue in the seed business (Poudel et. al, 2003). Marketing skills of members and access to market network is crucial for sustainability of farmer managed seed production system (Poudel et al, 2003; Witcombe et al 2010).

\section{Objective}

The objective of this research is to analyse the contributing factors for success and failure of farmers' organizations for field crop seed multiplication at the community level. The findings of this study are expected to contribute in programme planning of the government and non government organizations in logical way to develop the viable FOs in seed business. 


\section{Materials and method}

This study follows qualitative and qualitative approach. A case study of successful and unsuccessful farmer' organizations involved in field crop seed multiplication was carried out in Banke and Bardiya districts during April-May, 2012. These districts were getting priorities for field crop seed production from SCDP period to till the date (ADB, 1999; and CDD, 2011), and thus selected purposively for this study. The three inactive ARCs, at Machhagad and Khairapur of Bardiya and Bankatawa of Banke district, represent the failure case. The two vibrant cooperatives, which were actively involved in field crop seed multiplication during the study period, namely Budhan Farmers Multipurpose Model Cooperatives (BFMMC), Padnaha in Bardiya and KUMC, Betahani in Banke represent the success case for this research.

Primary data were collected through focus group discussions, interview with key informants, and survey. The questionnaire were developed, tested and reproduced separately for focus group discussion, key informant interview and the survey. Five focus group discussions in total (one in each of three ARCs and two cooperatives) were carried out with semi structured questionnaires pertaining to initiation of seed production, group development, quality control, marketing and income from seed business. The records of ARCs and cooperatives were accessed to get the details of their activities. Key informants, 10 in total (two from each) were interviewed to get details on seed production, collection and prices. A survey was conducted to gather the quantitative data of farmers' income and market price of seeds. Thirty farmers in total taking 15 from each of two cooperatives selected randomly and interviewed with closed questionnaire to record the income from seed business. Two agro vets in each study districts were visited to gather the price information of cereal and pulse crop seeds. Secondary data was collected to describe and verify the findings of the study through printed reports and web searches.

\section{Results and discussion}

The factors accounting for success and failure of FOs in seed business, based on this research, are presented as group internal factors, extension service for FOs, seed quality control and seed marketing subheadings in this report.

\section{Internal factors of FOs}

Group internal factors includes cohesion and cooperation among members, leadership styles, members participation and commitment, planning and decision making, age of farmer groups, interpersonal relationship between members, conflict of interest, and communication within group (Chamala, 1995). Among the group internal factors; interest and initiatives of members, autonomy of group actions, conflicts, and members' participation were found the most influential for performance of seed production FOs (Table 1).

Interests and initiatives of beneficiaries are powerful forces behind the development of successful farmers' group (Pandey and Ross, 2006). Contrary, the establishment of ARCs and their enterprise selection was made in the interest and initiatives of the SCDP (Table 1), and was tried to translate it 
as the interest of farmers in ARCs. Consequently, the ARCs could not accept the seed business as their own enterprise rather a programme implemented for project purpose.

Leaders were selected democratically in regular interval of one to two years in both types of cases studied. These leaders were allocating enough time for group activities, but the lack of coordination and management skills hindered them develop linkages with market and run the regular activities smoothly in ARCs. Pandey and Ross (2006) also discovered the lack of coordination and members' participation in unsuccessful FGs in Nepal. It was also found that males were dominating, and women participation was not recognised in ARCs. The undisclosed conflicts between ARC members became persistent after the termination of the project in absence of external facilitation and sense of ownership among members (Table 1). Conflicts in ARCs apparently had their root in urge of some members to fulfil their social needs, for instance, achieving power in ARCs. This was first noticed in ARC Machhagad and Bankatwa. Members were divided into different interest subgroups, and the power exercise between them created disharmony and weakened working relations among members. Maintaining good working relationships among members is necessary for effectiveness of group (Johnson and Johnson, 1997 cited in Pandey and Ross, 2006), but it was lacking in ARCs. Consequently, monthly meetings became scanty having low attendance rates, and the willingness of members sharply inclined towards reluctance to abide by norms.

Table 1. Distinguishing attributes of FOs

\begin{tabular}{lll}
\hline \multicolumn{1}{c}{ Descriptions } & \multicolumn{1}{c}{ Cooperatives (success case) } & \multicolumn{1}{c}{ ARCs (failure case) } \\
\hline $\begin{array}{l}\text { Formation } \\
\text { Selection of enterprise }\end{array}$ & $\begin{array}{l}\text { Farmers initiatives } \\
\text { Farmers themselves } \\
\text { Minimum at beginning, continued } \\
\text { and optimised with group } \\
\text { requirement } \\
\text { Consultative type }\end{array}$ & $\begin{array}{l}\text { External initiatives } \\
\text { External influence } \\
\text { High at the beginning but later } \\
\text { discontinued }\end{array}$ \\
$\begin{array}{l}\text { Type of extension } \\
\text { Decision making }\end{array}$ & Participative & Directing / Rowing type \\
$\begin{array}{l}\text { Conflicts of interests } \\
\text { linkage with seed }\end{array}$ & Rarely observed, and managed & $\begin{array}{l}\text { Persistently observed and not } \\
\text { managed }\end{array}$ \\
$\begin{array}{l}\text { Group activities } \\
\text { Seed selling }\end{array}$ & Partially developed & No linkage developed \\
\hline
\end{tabular}

Decision making in ARCs was highly influenced by service providers. Lack of members' participation in decision making is another cause of a group being ineffective (Johnson and Johnson, 1997, cited in Pandey and Ross, 2006). Low level of members' participation resulted the lack of ownership, planning and problem solving skill among them.

ARCs though have developed welfare fund and large proportion of this fund was invested among members but not became able to maintain financial discipline. Cases of financial cheatings were observed in ARCs as exemplified by reluctance of members to repay loan and preparation of fraud papers. Cheatings were observed mostly when the internal conflict was at peak period. Rescue 
mechanism for retrieving the money was very weak in ARCs. Members' trust and commitment for ARCs gradually declined.

They were making decision in own understanding and consensus in participative way. DADO was supporting them from the beginning but with minimum interference. This process has promoted decision making capacity of members of cooperatives. Interestingly, they have selected the seed production as main enterprise in their own interest and consensus. It has created deep sense of ownership and accountability among members. Ownership development among the members has promoted organizational stability of cooperatives. They were developing production and marketing plans in own efforts. Cooperatives were regularly collecting the monthly cash deposits from members. The KUMC was disbursing short term loans to its members to buy source seeds and the BFMMC was investing in storage structures and machinery from reserve deposits. Persisting conflict and financial cheatings were not reported in cooperatives. However, women participation was still low in both cooperatives (Annex1).

\section{Extension service for FOs}

The success and failure of FOs largely depend on the nature of extension service provided (Chamala, 1995). The ARCs were closely supervised and intensively supported during the SCDP period. The project efforts became able to increase the seed production during project period. However, project outputs could not integrated in regular programme of DADOs in the absence of exit policy ensuring slow removal of supports. Gradually developing the FOs allows time for members to self-select themselves and develop their own vision (Abaru et. al, 2006), but ARCs were developed hastily with the implementation of the project. Capital supports (storage, grading machines) were provided irrespective of their organizational maturity that ultimately gets wasted in three ARCs. The continuous supervision of DADO kept ARC Betahani alive, but their seed businesses get expanded only after the conglomeration with the KUMC. Contrary to ARCs, cooperatives were supported by government with small scale storage facilities at the beginning, and additional supports for storage and grading were provided when these cooperatives reflected organizational stability and continuity of seed business.

Extension services for ARCs were lacking on organizational management and business skill development support, focus was on production dimension only. ARCs could not link themselves with seed market after project termination. Poudel et al, (2003) found the lack of group strengthening supports; marketing skills and withdrawal of subsidies were the reasons of failure of most of the FGs developed by Special Programme in Nepal (SPIN) after its termination. Government extension service still has emphasis on production dimensions. Providing marketing skills along with technical skills are crucial to make seed business successful (Witcombe, et al. 2010). Moreover, this study reveals the need of emphasizing organizational management of FOs for their viability in seed business.

The sustainability of technologies promoted by the SCDP is in question. The imported seed grading machines could hardly be operated by ARCs. Technicians were not available in nearby areas for repair and maintenance of the grader. The project provided Rhizobium inoculums for pulses, but it was not available for farmers after the project termination. This reduced the yield of pulses as exemplified in command area of ARC Machhagad and Bankatawa. 
Due to escalating Maoist war, Social environment was not conducive to strengthen the business, and this has badly affected the group activities in ARCs. Persistent fear in society and transportation blockage has badly affected the working environment and motivation of members. Seed multiplication was halted for 3 years (2005-2007) in ARC Betahani as their go down was forcibly occupied by Maoists.

\section{Seed quality control}

Seed quality is an important factor for economic benefit for seed producers in long term (Thijssen et al, 2008). It is interesting that the seed quality was satisfactory, and not a limiting factor for business expansion in both types of cases studied. The common ways found for seed quality control are discussed herein below.

\section{Selecting Farmers}

ARCs were practicing 'clustering' of land for seed production during SCDP period. Selecting 'trustable and willing' farmers is a common strategy of both cooperatives for quality maintenance. In the rural clusters, it is possible that one member could watch over the neighbouring member and vice versa. This is helpful for mutual vigilance of seed grower's activities, thereby minimizing the chances of mixing the seeds.

\section{Monitoring team}

Monitoring teams were formed in both cooperatives, but not in ARCs. The actual name may vary; for instance, field inspection team or technical team. The job of monitoring team is to select the seed growing farmers, and monitor their seed production activities. The team coaches farmers if necessary. The team found around $40 \%$ of rice seed plots were not meeting the standard, and not accepted as seed crop in 2010 at BFMMC. Such team was working very well in KUMC Betahani too.

\section{Regulatory role of service agency}

Seed Act of Nepal specifies that seed certification is done by Central or Regional seed testing laboratories. This act also specifies the role of public seed certifying body from production stage to threshing stage of certified seeds. The legal provisions has inspired the Cooperatives to obey the instructions given by Regional Seed Testing Laboratory (RSTL), Khajura pertaining to seed quality maintenance. In addition, DADOs, Regional Agriculture Research Station, Khajura are regularly providing technical services for production and quality control. Advanced Technical services were provided to expand the scope of seed production by enabling cooperative for foundation seed production (Table 5).

\section{Economic benefits}

Seed production is the main source of income for farmers and they do not want to lose it. Income from seed constitutes $70 \%-100 \%$ of total farm income of seed growers (Table 2). The income from seed production ranges minimum Rs 15,000.00 to maximum Rs 2, 00,000.00 per household. Farm 
income is the major source of income (contributing $>50 \%$ of total income) for $63.3 \%$ (19 out of 30) of surveyed farmers (Table 2 and 3). It is interesting that all the members involved in focus group discussion in non functional ARCs (total 18; taking 6 from each ARC) agreed that seed multiplication was economically beneficial for them, and they were interested to produce seeds again if proper marketing mechanism is developed.

Table 2. Contribution of seed sector in farmers' income

\begin{tabular}{llll}
\hline $\begin{array}{c}\text { Farm Income range } \\
\text { (Rs'000) }\end{array}$ & \multicolumn{1}{c}{ Frequency } & \multicolumn{1}{c}{$\begin{array}{c}\text { Part of farm income by } \\
\text { seed }\end{array}$} & Frequency \\
\hline$\leq 50$ & $13(43.3 \%)$ & $\leq 25 \%$ & $3(10 \%)$ \\
$51-100$ & $9(30 \%)$ & $26-50 \%$ & $8(26.7 \%)$ \\
$101-150$ & $5(16.7 \%)$ & $51-75 \%$ & $12(40 \%)$ \\
$151-200$ & $3(10 \%)$ & $76-100 \%$ & $7(23.33 \%)$ \\
\hline
\end{tabular}

\section{Seed marketing}

The competition was mainly with private seed companies operating in study districts and seed cooperatives of Chitwan district. Price negotiations, discounts and selection of popular varieties were the common tools of KUMC and BFMMC to sustain in competition market. Cooperatives tend to sale in low prices if buyer wants to purchase in big quantity. There is $10 \%$ reduction in price for customers buying more than $1 \mathrm{MT}$ of seeds. Cooperatives may further reduce the price if a customer buys the substantially higher volume. Both Cooperatives have tendency to grow the popular varieties rather than newly released varieties to minimize the marketing risk and the varieties grown were recommended for terai region only. The price difference of seeds at producer and consumer level is more in maize, wheat and lentil than rice (Table 3). This difference may be due to processing cost involved, and level of production and demand. Pricing and payment

The cooperatives are facing the deficiency of cash reserves to purchase the seed from producers. Foundation seeds are paid higher premium price 30-35\%) than certified seeds (10-15\%) over the grain price. Raw seed from producers is accepted by cooperatives in two ways: either by immediately paying the producers or in rental term where producers are paid after selling the cleaned seed. In the later case, Cooperatives charges up to Rs 5.00 per as processing and packaging fee per $\mathrm{kg}$ of seed; the remaining money from the final price of cleaned seeds goes to producer farmers. The price paid to producers becomes quite higher in rental term compared to immediate payment. Farmers, who are relatively well off, have preference to sale in rental term, while the cooperatives have preference to buy with immediate payment. The BFMMC was able to pay only 8 farmers out of 45 rice seed growers in 2012 due to limited cash reserves. Poor farmers are paid with priority. Seeds from rest of the farmers were accepted in rental term. Financing arrangements for cooperatives are still lacking. The banks ask for big collateral, and if collateral is organised, the rural land where cooperatives are located is valuated very low price than the actual price of it. Hence, the actual loan payable to cooperatives is small not enough to fulfil their requirement. The interest rates of banks for agricultural activities are relatively high, around $15 \%$. So, cooperatives do not prefer to take loan from banks. There are no other sources of finance for cooperatives in low interest rates. 
Table 3. Price of seed at various levels 2012 (Rs/kg)

\begin{tabular}{lccc}
\hline Crop & Farmers & Cooperatives & Agro vets \\
\hline Rice & 22 & 31 & 37 \\
Wheat & 19 & 23 & 42 \\
Lentil & 60 & 100 & 120 \\
Maize & 23 & 45 & 80 \\
\hline
\end{tabular}

\section{Demand collection}

Demand collection by seed groups is the key success factor in selling seeds (Witcombe et. al 2010). Regularity of contact between seed cooperatives and traders through visits and stakeholders' workshop were found effective tools of demand collection and developing linkages between them. It is observed that basis of demand estimation could be formal and rigid in early stage and tends to become informal and flexible in long term along with brand and network development.

\section{Production planning and sale of seed}

The total seed production is increasing in cooperatives for rice and wheat (Table 4). The sale volume, feedback received, and influx of customer in previous year give an idea of seeds to be produced by the cooperatives this year. Among the other reasons, limited storage capacity of cooperatives was one of key factors that hindered them to expand the production volume in early years of establishment. Massive supports from government and non government sector in recent years have solved the storage problem. The collection of rice seeds in BFMMC dwindled in 2012 (Table 4) due to inability of cooperative to make immediate payment of raw seeds. The producers have to take back the unsold seeds and also bear the cleaning fees involved. Moreover, amidst the possibilities of cleaned seed being not sold, farmers either sold part of their seeds in grain market or consumed themselves due to financial shortfall.

Table 4. Seed production status in Cooperatives

\begin{tabular}{|c|c|c|c|c|c|c|c|c|c|c|c|}
\hline \multirow{4}{*}{ Year } & \multicolumn{11}{|c|}{ Cooperatives } \\
\hline & \multicolumn{6}{|c|}{ BFMMC } & \multicolumn{5}{|c|}{ KUMC } \\
\hline & \multicolumn{5}{|c|}{ Crops } & \multirow{2}{*}{ Total } & \multicolumn{4}{|c|}{ Crops } & \multirow{2}{*}{ Total } \\
\hline & Rice & Wheat & Maize & Pulse & Oilseed & & Rice & Wheat & Maize & Pulse & \\
\hline 2012 & 100 & 34 & 3 & 5 & 3 & 145 & 60 & 70 & 3 & 15 & 148 \\
\hline 2011 & 165 & 24 & 3 & 5 & 3 & 200 & 56 & 40 & 2 & 12 & 110 \\
\hline 2010 & 125 & 15 & 2 & 4 & & 146 & 40 & 35 & & 12 & 87 \\
\hline
\end{tabular}

Cooperatives have limited access in markets outside the respective districts. They are increasingly using mass media, for instance pamphlets and local FM radios, for publicity and advertisement but these are confined to few nearby districts. It might be the reason of local end users being the major buyers who purchased around 50\% of total volume in 2012 (Table 5), however the customer composition was slightly varying every year. Cooperatives outside the districts (e.g. from Chitwan), NGOs, Private seed companies (local and outsiders) are not the regular customers. Seed market chain is short (Fig.1), it has provided the free flow of feedback from end users and rest of chain actors up to seed FOs and producer farmers. Foundation seeds are mainly sold to certified seed producers within cooperatives. 
David \& Sperling (1999) reported the farmers' network was inefficient to spread seeds of improved varieties among farmers. However, an excellent example of inter-group linkage for improved seed distribution up to farming communities was discovered in this research. A number of FGs and farmers' cooperatives within the respective districts accumulated seed demand from members and purchased the required volume of certified seed directly from BFMMC and KUMC (Table 5). The network development and interconnectedness with other groups have impact on group performance in marketing of commodities (Abaru, et al., 2006).

Table 5. Customers composition in 2011/12 (amount in mt)

\begin{tabular}{|c|c|c|c|c|c|c|c|c|c|c|}
\hline \multirow{2}{*}{ Cooperative } & \multicolumn{8}{|c|}{ Customers and purchase volume } & \multirow{2}{*}{$\begin{array}{c}\text { Sale } \\
\text { within } \\
\text { the } \\
\text { district }\end{array}$} & \multirow{2}{*}{$\begin{array}{c}\text { Found } \\
\text { ation } \\
\text { seed }\end{array}$} \\
\hline & Agro vets & NGOs & DADO & VDC & FOs & IF & PSC & Total & & \\
\hline BFMMC & 20 & & 1 & 10 & 35 & 67 & & $143 *$ & 120 & 11 \\
\hline KUMC & 18 & 12 & 4 & & 28 & $73 * *$ & 13 & 148 & 125 & 15 \\
\hline
\end{tabular}

(Note: * $10 \mathrm{mt}$ remained unsold, **15 mt rice seed of Radha- 4 Variety was purchased by Indian farmers, VDC: Agriculture Service Centre buys with the budget allocated by Village Development Committees to distribute locally, IF: Individual Farmers, PSC: Private Seed Companies)

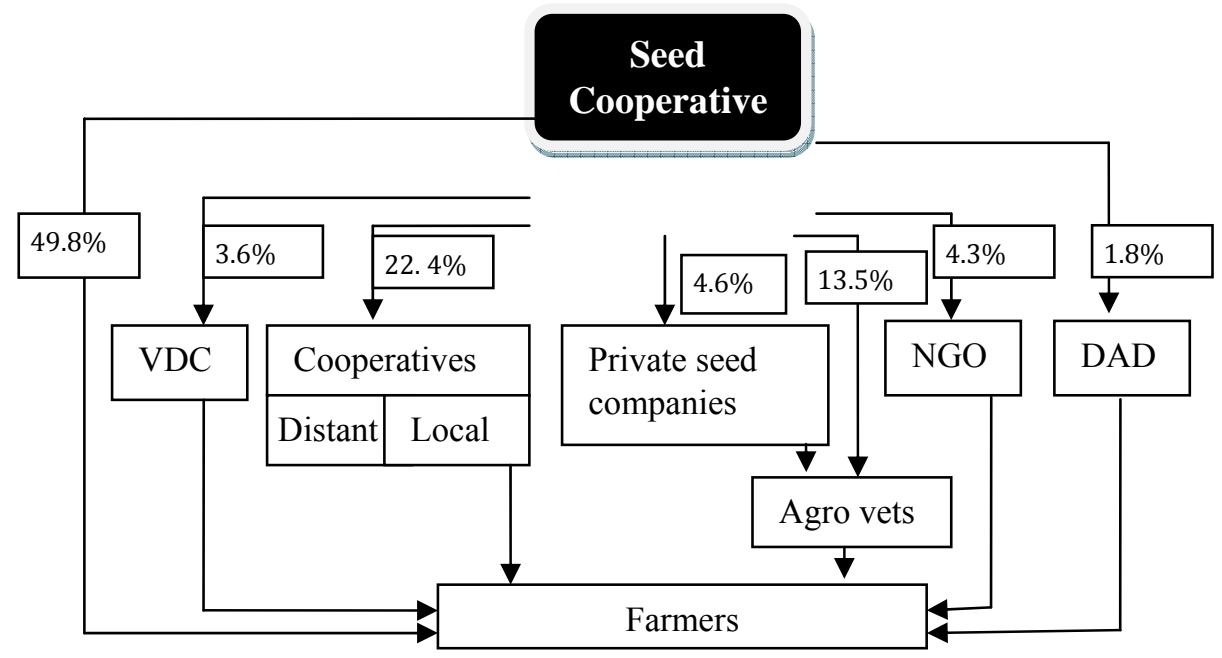

Fig 1. Seed marketing chain

Nevertheless, occasional cases of unsold seeds were reported due to inadequate outreach activities, and escalated demand estimation. Ten $\mathrm{mt}$ of rice seeds at BFMMC in 2011 and $25 \mathrm{mt}$ of rice seeds at KUMC in 2010 remained unsold and later sold in grain market by producers. Financial capacity of farmers and cooperatives, and market assurance are the key factors that affect the seed collection from producers. Indian farmers are buying the Radha- 4 variety from the cooperatives, but the organised efforts are lacking to export the seed 


\section{Packaging}

Logo of cooperatives, year of production, crop, variety, level of seed, and lot number is mentioned in seed bags. The producer farmers can be traced on the basis of lot number mentioned in each seed bag. Such transparency in seed market chain was found to have self controlling effect on producers and processors for quality maintenance.

A model for extension services for farmers' organization has been depicted (Fig.2). This model suggests pros and cons of seed extension services in order to strengthen FO of seed production for major crops.

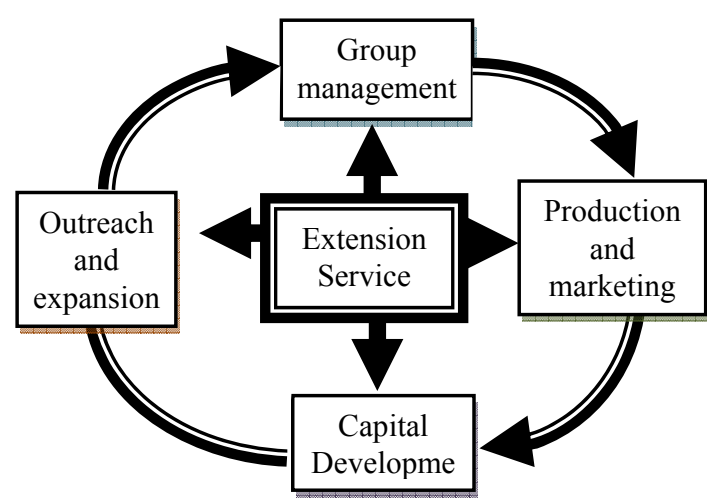

Group Management

- self selection for membership

- enterprise selection

- norms setting

- decision making and record keeping

- group action planning

- fund collection, loan and recovery

- responsibility sharing

- self monitoring and democracy

Figure 2: Watch Model of extension services for seed FOs

Farmers' organizations developed in their own initiatives have shown better performance than those formed in external initiatives. Need of internal control mechanism to check the financial cheating was clearly observed in FGs. There is lack of guidelines for development and supporting seed groups in Nepal. Farmers' organizations are often promoted by agriculturists who are not well trained about group management, accounting and loan recovery methods.

Inter-group linkages seem the most feasible way of distributing seeds of desired variety to farming communities in reasonable cost, and increase the seed replacement rates (SRR). Regular interaction with stakeholders and advertising through mass media are found effective tools for network development and sale promotion. Internal arrangement by FOs and economic benefits from enterprise (market control) are the key factors for seed quality control. Subsidy should be provided for the seeds of newly released varieties to promote their use at farming level. Cooperatives have great scope for expanding seed sale by diversifying seed production viz. maize, hill varieties of cereals and approaching the distant markets. 


\section{Conclusion}

ARCs were collapsed due to the lack of ownership, group management skill and inability to link with market. Project outputs were not integrated in regular programme of DADO. The business skills, technical skills and organizational management skills of ARC members were not promoted parallel. Autonomy and adequacy of time given to select the enterprise for groups has long term impact on ownership development. High level of external influence lead ARCs for dependency and lack of problem solving ability among members. The extension service should be consultative type and optimised with maturity of groups. Such supports must be gradual and provided in a logical way. The service agency support should logically be provisioned until the groups become able to self propel their activities. Based on findings of this study, a 'watch model' (Figure 2) of extension support for FOs is proposed. Extension service should have emphasis on four dimensions: Group management dimension at beginning of FOs development and move gradually in clockwise direction towards Production and marketing, Capital development, and Outreach and expansion dimensions. However, there may be overlapping of service to some extent, minor supports might be on consecutive dimensions while the major emphasis is on specified dimension.

\section{References}

Abaru, M B, A Nyakuni, and G Shone. 2006. Strengthening farmers' organizations: The experience of RELMA and ULAMP. World Agro forestry Centre, Nairobi.

ADB. 1999. Project completion report on the secondary crop development project in the Kingdom of Nepal. Asian Development Bank, Manila.

Almekinders, CJM, NP Louwaars and GH De Bruijn. 1994. Local seed system and their importance for improved seed supply in developing countries. Euphytica, Vol.78, pp 207-216.

CDD. 2011. Annual progress report of Crop development Programs in FY 2067/68 (in Nepali). Crop Development Directorate (CDD), Hariharbhavan, Latitpur.

Chamala, S. 1995. Group Effectiveness: From Group effectiveness Method to Participative, Community Landcare Groups' in: Participative approach for landcare: perspective, policies, programmes, eds Chamala, S and K Keith, Australian Academic Press, Bowden Hills, QLD, PP 73-92.

DADO. 2011a. Annual progress report (in Nepali). District Development Offices, Banke.

DADO. 2011b. Annual progress report (in Nepali). District Development Offices, Bardiya.

David, S and L Sperling. 1999. Improving technology delivery mechanisms: Lessons from bean seed systems research in eastern and central Africa. Agriculture and Human Values Vol.16: PP 381-388.

Guei, R G. 2010. Promoting the growth and development of smallholder seed enterprise for food security crops. Food and Agriculture Organization of United Nations. 
Louwaars, N P. 1995. Policies and strategies for seed system development in: Integrating seed systems for annual food crops, eds Amstel, H.V, J.W.T. Bottema, M. Sidik and C.E. van Santen (CGPRT No. 32): CGPRT Centre.

Pandey, A and H Ross. 2006. Factors Influencing Group Process in Agriculture Extension: A Comparison of Group Processes in Farmers Groups in Nepal and in the International Literature. Agriculture Development Journal, Vol. 3(3): 85-101.

Pokhrel, S. 2012. Role of DISSPRO and CBSP on Current Seed Supply Situation in Nepal. Journal of Agriculture and Environment. Vol. 13, PP 53-59.

Poudel, D, P Chaudhary, KR Chowin, H Ghimire. 2003. Case studies of seed production and marketing through farmers' groups in Nepal. CAZS and University of Wales.

Thijssen, MH, Z Bishaw, A Beshir, and WS de Boef, eds. 2008. Farmers, Seed and Varieties: Supporting Informal seed Supply in Ethiopia. Wageningen International.

Witcombe, JR, KP Devkota, and KD Joshi. 2010. Linking Community Based Seed producers to markets for a sustainable seed supply system. Expl Agric [e-journal]: vol. 46 (4), pp. 425-437. 